Manoj Saxena

Paul Young

David Pilcher

Michael Bailey

David Harrison

Rinaldo Bellomo

Simon Finfer

Richard Beasley

Jonathan Hyam

David Menon

Kathryn Rowan

John Myburgh

Received: 14 October 2014

Accepted: 20 January 2015

Published online: 3 February 2015

(C) The Author(s) 2015. This article is published with open access at Springerlink.com

Take-home message: (1) This paper suggests that early fever in the context of meningitis and encephalitis is not associated with increased hospital mortality; it is possible that early fever may in fact be beneficial for this patient population. (2) For traumatic brain injury and stroke, early temperature between 37 and $39^{\circ} \mathrm{C}$ is not associated with increased hospital mortality; however, for these patient populations early temperature below $37^{\circ} \mathrm{C}$ and above $39^{\circ} \mathrm{C}$ is associated with increased hospital mortality.

Registered with the Australian Clinical Trials Registry: ACTRN12611001218987 (https://www.anzctr.org.au/registry/trial_ review.aspx? ID=347753).

An abstract of preliminary data from this manuscript ("Early temperature and mortality in critically ill patients with acute neurological pathology") was presented at the Canadian Critical Care Forum in Toronto, Canada (November 2012). http://www.criticalcarecanada.com/ abstracts/2012/early_temperature _ and_mortality_in_critically_ ill_patients_with_acute_ neurological_pathology.php.

Electronic supplementary material

The online version of this article (doi:10.1007/s00134-015-3676-6) contains supplementary material, which is available to authorized users.

\title{
Early temperature and mortality in critically ill patients with acute neurological diseases: trauma and stroke differ from infection
}

M. Saxena (西) - S. Finfer · J. Myburgh Critical Care and Trauma Division, George Institute for Global Health, Sydney, NSW, Australia

e-mail: m.saxena@unsw.edu.au

M. Saxena - J. Myburgh

St George Hospital Clinical School,

University of New South Wales, Sydney, NSW, Australia

P. Young

Intensive Care Unit, Capital and Coast District Health Board, Wellington Regional Hospital, Wellington, New Zealand

P. Young - R. Beasley

Medical Research Institute of New Zealand, Wellington, New Zealand

D. Pilcher · M. Bailey · R. Bellomo

Australian and New Zealand Intensive Care Society Centre for Outcome and Resource Evaluation, Melbourne, VIC, Australia

\section{Pilcher}

Australian and New Zealand Intensive Care Research Centre, School of Public Health and Preventive Medicine, Monash

University, Melbourne, VIC, Australia

\section{Pilcher}

Department of Intensive Care, The Alfred Hospital, Commercial Road, Prahran, VIC, Australia

D. Harrison · K. Rowan

Intensive Care National Audit and Research Centre, London, UK

\section{S. Finfer}

Sydney Medical School, University of Sydney, Sydney, NSW, Australia

\section{J. Hyam}

Victor Horsely Department of Neurosurgery, National Hospital for Neurology and Neurosurgery, Queen Square, London, UK

\section{Menon}

Division of Anaesthesia, University of Cambridge, Cambridge, UK

Abstract Background: Fever suppression may be beneficial for patients with traumatic brain injury (TBI) and stroke, but for patients with meningitis or encephalitis [central nervous system (CNS) infection], the febrile response may be advantageous. Objective: To evaluate the relationship between peak temperature in the first $24 \mathrm{~h}$ of intensive care unit (ICU) admission and all-cause hospital mortality for acute neurological diseases. Design, setting and participants: Retrospective cohort design from 2005 to 2013, including 934,159 admissions to 148 ICUs in Australia and New Zealand (ANZ) and 908,775 admissions to 236 ICUs in the UK. Results: There were $53,942(5.8 \%)$ patients in ANZ and $56,696(6.2 \%)$ patients in the UK with a diagnosis of TBI, stroke or 
CNS infection. For both the ANZ $(P=0.02)$ and UK $(P<0.0001)$ cohorts there was a significant interaction between early peak temperature and CNS infection, indicating that the nature of the relationship between in-hospital mortality and peak temperature differed between TBI/stroke and CNS infection. For patients with CNS infection, elevated peak temperature was not associated with an increased risk of death, relative to the risk at 37-37. $4{ }^{\circ} \mathrm{C}$ (normothermia). For patients with stroke and TBI, peak temperature below $37{ }^{\circ} \mathrm{C}$ and above $39^{\circ} \mathrm{C}$ was associated with an increased risk of death, compared to normothermia. Conclusions: The relationship between peak temperature in the first $24 \mathrm{~h}$ after ICU admission and in-hospital mortality differs for TBI/stroke compared to CNS infection. For CNS infection, increased temperature is not associated with increased risk of death.

Keywords Temperature - Mortality · Stroke - Traumatic brain injury · Meningitis · Encephalitis

\section{Introduction}

Acute illnesses affecting the central nervous system (CNS), such as stroke [including ischaemic stroke, intracerebral haemorrhage and subarachnoid haemorrhage (SAH)], traumatic brain injury (TBI) and CNS infection (meningitis and encephalitis), are globally major causes of disability and death [1]. Fever, defined as a temperature of $37.5^{\circ} \mathrm{C}$ or above $[2,3]$ in this context, is common in the early phase of these acute illnesses [2-7], as is the use of pharmacological and physical interventions for the purpose of fever suppression [4, 8, 9]. However there remains clinical uncertainty about the biological purpose of fever $[10,11]$ and the therapeutic efficacy of the interventions [7, 12-14] used for fever suppression in these patient populations.

For patients with non-infective CNS conditions, such as stroke and TBI, animal models suggest that fever may further exacerbate neuronal damage [15-18] following the initial vascular or traumatic insult. Additionally, observational clinical studies suggest an association between raised temperature after both TBI [4, 6] and stroke [2, 3, 5, 19-21] and increased morbidity and mortality [22].

In general, among patients with an inflammatory response as a consequence of an infection, the development of a fever may be part of a phylogenetic, protective host response $[10,11,23]$ to an invading infective agent. Several observational studies suggest that for patients with systemic infections, an elevated temperature is associated with decreased mortality [24-26]. Additionally, antipyretic use is associated with harm for patients with systemic infection [25]. Finally, certain microbial strains that cause CNS infection (Neisseria meningitides [27] and Streptococcus pneumonia [28]) are inhibited from replication at temperatures within the febrile pathophysiological range. Therefore it is biologically plausible that the observational relationship between fever and morbidity and mortality may differ for patients with CNS infection, compared to those with TBI/stroke.

We undertook a retrospective analysis of two independent international intensive care databases in order to test the hypothesis that early fever would have an independent association with worse outcome for TBI and stroke, but not for CNS infection. Specifically, we hypothesized that elevated peak temperature during the first $24 \mathrm{~h}$ after intensive care admission would be associated with increased mortality in patients admitted with an admission diagnosis of TBI or stroke, but not in patients with a diagnosis of CNS infection.

\section{Methods}

\section{Study design}

This retrospective cohort study evaluated the association between peak temperature recorded in the first $24 \mathrm{~h}$ of intensive care unit (ICU) admission and all-cause inhospital mortality among critically ill patients with TBI, stroke and CNS infections.

\section{Participants and setting}

All patients admitted to an adult ICU at one of 148 centres in Australia and New Zealand (ANZ) or one of 236 centres in the UK between 2005 and 2013 were eligible for inclusion in this study if the admission diagnosis to the ICU was attributable to an acute neurological disease. We defined an acute neurological disease as TBI, stroke (ischaemic stroke, subarachnoid haemorrhage, intracerebral haemorrhage) or CNS infection (meningitis or encephalitis) according to the coding systems of the Australia and New Zealand Intensive Care Society Adult Patient Database (ANZICS-APD), using the Australia and New Zealand Risk of Death Model (ANZROD) [29], and the UK Intensive Care National Audit \& Research Centre Case Mix Programme Database (ICNARCCMPD), using the ICNARC Coding Method (ICM) [30].

We excluded patients who had cardiopulmonary resuscitation in the previous $24 \mathrm{~h}$ because of the confounding effect of therapeutic hypothermia; patients with missing data for temperature, admission diagnosis, vital status at hospital discharge and patients with insufficient information on the Glasgow Coma Score (GCS). Where 
patients were admitted to ICU more than once during an acute hospital admission, only the patient's first admission was included in the analysis.

\section{Databases}

ANZ data were extracted from the ANZICS-APD and UK data were extracted from the ICNARC-CMPD. The ANZICS-APD is an established binational, representative [31] voluntary database, which has been well described and contains data for more than one million ICU admissions [32]. Data are collected under the Quality Assurance Legislation of the Commonwealth of Australia (Part VC Health Insurance Act 1973, Commonwealth of Australia). In New Zealand, use of anonymous quality data for research is classified as 'low risk audit activity' and is exempt from requirements for formal ethics approval. Access to the data was granted by the ANZICS Centre for Outcome and Resource Evaluation (CORE) Management Committee. Ethics approval was obtained from the Alfred Hospital Human Research Ethics Committee (HREC reference number 183/11) in keeping with ANZICS CORE publication policies for use of the APD. The ICNARC-CMPD is a trinational, representative database with coverage of adult general critical care units and specialist neurocritical care units in England (92\%), Wales $(100 \%)$ and Northern Ireland $(100 \%)$. The ICNARC-CMPD contains over one million adult critical care admissions [33]. The ICNARC-CMPD has support for the collection and use of patient identifiable data without consent under Section 251 of the NHS Act 2006 (approval number PIAG 2-10(f)/2005).

\section{Variables}

The following variables were extracted from the databases: age, sex, GCS, physiological measures including temperature in the first $24 \mathrm{~h}$ and vital status at hospital discharge. Additionally, illness severity was determined using the APACHE II risk prediction model for both databases [34], the ANZROD [29] model for the ANZ data and the ICNARC model for the UK data [30]. Neither database contained information on how temperature was measured or information regarding pharmacological agents that may be used to modify temperature or the use of physical cooling.

\section{Outcomes}

The primary outcome was in-hospital mortality (all-cause death before hospital discharge). For patients in the ANZ database, vital status was determined at the time of discharge from the acute hospital housing the ICU to which the patient was admitted. For patients in the UK database, vital status was determined at the time the patient was ultimately discharged from any acute hospital (including transfers between hospitals).

Statistical methods

We considered peak temperature as a categorical variable, divided into $0.5{ }^{\circ} \mathrm{C}$ increments. We calculated odds ratios $(95 \% \mathrm{CI})$ for the risk of hospital mortality associated with peak temperature in the first $24 \mathrm{~h}$ after ICU admission for all patients (univariate model). Except for the group with peak temperatures below $36.0^{\circ} \mathrm{C}$, which is reported as a single category, we report odds ratios relative to a normal temperature defined as a peak temperature of $37.0-37.4{ }^{\circ} \mathrm{C}$ based on data from observational clinical studies $[2,3]$. We then performed a multivariate analysis for hospital mortality using temperature as a categorical variable (as defined above), GCS and illness severity (APACHE III model for the ANZ cohort and the ICNARC model for the UK cohort). Both illness severity models used the predicted $\log$ odds of death, excluding the GCS and temperature weightings.

We chose to combine TBI $[4,6]$ and stroke $[2,3,5$, 19-21] because of the consistent finding that elevated temperature [22] is associated with adverse morbidity and mortality in previous observational studies. To confirm that this approach was reasonable, we separated the TBI/ stroke group into three groups [TBI, haemorrhagic stroke (subarachnoid haemorrhage, intracerebral haemorrhage) and acute ischaemic stroke (AIS)] and evaluated the relationship between peak temperature in the first $24 \mathrm{~h}$ and all-cause hospital mortality using univariate and multivariate analyses (as described above).

To establish if the relationship between temperature and hospital mortality differed between the TBI/stroke group and CNS infection, we fitted an interaction between temperature and the two groups. A two-sided $P$ value less than 0.05 was considered to be statistically significant. We first tested our hypotheses using the ANZ database. After this analysis was completed, we applied the same analysis to the UK database to validate the preliminary findings.

\section{Role of the funding source}

This study received no direct funding from peer-reviewed institutional granting agencies. Indirect (in-kind) support was received from the Australian and New Zealand Intensive Care Research Centre, Melbourne, Australia; the George Institute for Global Health, Sydney, Australia; The Medical Research Institute of New Zealand, Wellington, New Zealand; and the Intensive Care National Audit \& Research Centre, London, UK. Apart from the 
affiliated authors, these centres had no involvement in the study design; in the collection, analysis and interpretation of data; in the writing of the report and in the decision to submit the paper for publication. The corresponding author had full access to all the data in the study and had final responsibility for the decision to submit for publication.

\section{Results}

Over the study period from 2005 to $2013,934,159$ intensive care admissions were included in the ANZICSAPD and 908,775 in the ICNARC-CMPD (for flow diagram see ESM Fig. 1). Of these, 53,942 (5.8 \%) in ANZ and 56,696 (6.2\%) in the UK met the inclusion criteria for an admission diagnosis of $\mathrm{TBI} /$ stroke or a CNS infection. After excluding readmissions and admissions following cardiac arrest, 51,314 in ANZ and 53,781 in the
UK were eligible for the analysis, of which 10,172 $(19.2 \%)$ of ANZ patients and 2,347 (4.4\%) of UK patients were excluded from the analysis owing to missing data. For the ANZ data, there were no substantial differences between included patients and patients that were excluded because of missing data (ESM Table 2). For the UK data, patients that were excluded because of missing data had higher intubation and hospital mortality rates (76 vs. $70 \%$ and 45 vs. $33 \%$ respectively) than patients that were included in the analysis.

Admissions included in the ANZ database were drawn from 148 hospitals (27\% rural, $22 \%$ metropolitan, $22 \%$ tertiary and $29 \%$ private). Admissions included in the UK database were pooled from 236 adult critical care units. Of the 236 critical care units, $29 \%$ were in university hospitals, $17 \%$ were university-affiliated and $54 \%$ were in nonuniversity (district general) hospitals. Nine of the UK critical care units were dedicated specialist neurocritical care units and 15 were combined neuro/general critical care units in a regional neurosurgical centre.

Table 1 Baseline demographics, illness severity scores, acute physiology and hospital outcome

\begin{tabular}{|c|c|c|c|c|}
\hline & \multicolumn{2}{|l|}{ ANZ } & \multicolumn{2}{|l|}{ UK } \\
\hline & $\begin{array}{l}\text { TBI/stroke } \\
(n=38,679)\end{array}$ & $\begin{array}{l}\text { CNS infection } \\
(n=2,463)\end{array}$ & $\begin{array}{l}\text { TBI/stroke } \\
(n=45,038)\end{array}$ & $\begin{array}{l}\text { CNS infection } \\
(n=6,396)\end{array}$ \\
\hline Age (years) & $55(37-70)$ & $49(32-64)$ & $54(40-65)$ & $50(34-64)$ \\
\hline Gender/male, \% $(n)$ & $64 \%(14,500)$ & $56 \%(802)$ & $61 \%(27,257)$ & $55 \%(3,486)$ \\
\hline APACHE II score & $15(10-22)^{\mathrm{e}}$ & $16(11-22)^{\mathrm{e}}$ & $15.2(7.3)^{\mathrm{e}}$ & $15.7(7.1)^{\mathrm{e}}$ \\
\hline APACHE III score & $46(31-67)$ & $49(32-69)$ & N/A & N/A \\
\hline ICNARC physiology score & N/A & N/A & $16.3(8.0)$ & $17.5(7.8)$ \\
\hline APACHE II risk of death ${ }^{\mathrm{a}}$ & $0.19(0.08-0.39)$ & $0.13(0.06-0.26)$ & $0.32(0.16-0.58)$ & $0.15(0.08-0.26)$ \\
\hline APACHE III risk of death & $0.13(0.04-0.38)$ & $0.13(0.05-0.33)$ & N/A & N/A \\
\hline ICNARC risk of death $^{\mathrm{a}}$ & N/A & N/A & $0.27(0.11-0.54)$ & $0.13(0.06-0.29)$ \\
\hline Peak temp, ${ }^{\circ} \mathrm{C}^{\mathrm{b}}$ & $37.4(0.8)$ & $37.9(1.0)$ & $37.5(0.9)$ & $37.8(1.0)$ \\
\hline Sedated for entire of first $24 \mathrm{~h}$ & N/A & N/A & $34 \%(15,482)$ & $38 \%(2,449)$ \\
\hline \multicolumn{5}{|c|}{ GCS (if not sedated for entire first $24 \mathrm{~h})^{\mathrm{c}}$} \\
\hline Verbal & $3(1-5)$ & $3(1-5)$ & $2(1-5)$ & $2(1-5)$ \\
\hline Motor & $5(3-6)$ & $5(4-6)$ & $5(1-6)$ & $5(4-6)$ \\
\hline Eye & $3(1-4)$ & $3(2-4)$ & $3(1-4)$ & $3(2-4)$ \\
\hline Total & $9.9(4.6)^{\mathrm{e}}$ & $10.3(4.1)^{\mathrm{e}}$ & $9.2(4.7)^{\mathrm{e}}$ & $10.1(4.3)^{\mathrm{e}}$ \\
\hline Intubated, \% (n) & $61 \%(14,388)$ & $56 \%(804)$ & $70 \%(28,436)$ & $67 \%(3,844)$ \\
\hline $\mathrm{pH}^{\mathrm{d}}$ & $7.37(7.31-7.43)$ & $7.39(7.32-7.44)$ & $7.41(7.37-7.45)$ & $7.41(7.36-7.45)$ \\
\hline $\mathrm{PaO}_{2}, \mathrm{mmHg}^{\mathrm{d}}$ & $120(88-192)$ & $109(83-169)$ & $84(72-101)$ & $83(71-98)$ \\
\hline $\mathrm{FiO}_{2}^{\mathrm{d}}$ & $0.50(0.30-0.60)$ & $0.45(0.30-0.60)$ & $0.30(0.28-0.40)$ & $0.30(0.28-0.40)$ \\
\hline $\mathrm{PaCO}_{2}, \mathrm{mmHg}^{\mathrm{d}}$ & $39(35-44)$ & $38(34-43)$ & $37(33-41)$ & $37(32-42)$ \\
\hline Highest HR, beats per minute & $95(80-110)$ & $100(90-117)$ & $95(83-112)$ & $105(90-120)$ \\
\hline Lowest MAP/mmHg & $71(64-80)$ & $70(63-78)$ & $72(63-81)$ & $67(60-76)$ \\
\hline$\left(\right.$ Acute $\left.^{\mathrm{c}}\right)$ hospital mortality, $\%(n)$ & $22 \%(8,510)^{\mathrm{e}}$ & $12 \%(296)^{\mathrm{e}}$ & $35 \%(15,763)^{\mathrm{e}}$ & $19 \%(1,215)^{\mathrm{e}}$ \\
\hline \multicolumn{5}{|c|}{$\left(\right.$ Acute $^{\mathrm{c}}$ ) hospital length of stay, median days (IQR) } \\
\hline All patients & $12(5-24)$ & $12(7-24)$ & $14(4-38)$ & $17(9-38)$ \\
\hline Survivors & $15(7-28)$ & $13(7,24)$ & $24(10-52)$ & $18(10-40)$ \\
\hline Non-survivors & $4(2-9)$ & $10(4,24)$ & $4(1-10)$ & $11(4-28)$ \\
\hline \multicolumn{2}{|c|}{$\begin{array}{l}\text { Values are mean (SD), \% }(n) \text { or median (quartiles) } \\
\text { a UK: Based on } 2011 \text { UK recalibration } \\
\text { b Central or non-central temperature } \\
\text { c UK only } \\
\text { d } \mathrm{ANZ:} \mathrm{if} \mathrm{the} \mathrm{FiO}_{2} \text { is below } 0.5 \text {, then the lowest a }\end{array}$} & \multicolumn{3}{|c|}{$\begin{array}{l}\text { highest alveolar-arterial }(\mathrm{A}-\mathrm{a}) \text { gradient is recorded } \\
\left.\mathrm{a}=713 \times \mathrm{FiO}_{2}-\left(\mathrm{PaO}_{2}-\mathrm{PaCO}_{2}\right)\right] . \mathrm{UK} \text { : lowest arterial } \mathrm{PaO}_{2} \text { is } \\
\text { used } \\
\mathrm{e} \quad P<0.0001 \text { for comparison between } \mathrm{ANZ} \text { and } \mathrm{UK} \text { groups, and } \\
\text { comparison within ANZ and UK groups }\end{array}$} \\
\hline
\end{tabular}

used; if the $\mathrm{FiO}_{2}$ is above 0.5 , then the $\mathrm{PaO}_{2}$ associated with the 
Table 2 In-hospital mortality and odds ratio (unadjusted and adjusted) for hospital mortality, relative to normothermia (37-37.4 $\left.{ }^{\circ} \mathrm{C}\right)$, for ANZ patients

\begin{tabular}{|c|c|c|c|}
\hline $\begin{array}{l}\text { Peak temp } \\
\left({ }^{\circ} \mathrm{C}\right)\end{array}$ & $\begin{array}{l}\text { In-hospital mortality } \\
\text { deaths, } N(\%)\end{array}$ & $\begin{array}{l}\text { Unadjusted odds ratio for } \\
\text { in-hospital mortality }(95 \% \mathrm{CI})^{\mathrm{a}}\end{array}$ & $\begin{array}{l}\text { Adjusted odds ratio for in-hospital } \\
\text { mortality }(95 \% \mathrm{CI})^{\mathrm{b}}\end{array}$ \\
\hline \multicolumn{4}{|c|}{ TBI/stroke $(n=38,679)$} \\
\hline$<36.0$ & $505 / 1,139$ (44.3) & $3.63(3.20,4.13)$ & $2.36(1.98,2.82)$ \\
\hline $36.0-36.4$ & $572 / 2,215(25.8)$ & $1.59(1.43,1.77)$ & $1.62(1.40,1.87)$ \\
\hline $36.5-36.9$ & $1,117 / 6,273(17.8)$ & $0.99(0.91,1.07)$ & $1.14(1.03,1.27)$ \\
\hline $37.0-37.4$ & $1,871 / 10,407(18.0)$ & 1.00 & 1.00 \\
\hline $37.5-37.9$ & $9,074 / 1,797$ (19.8) & $1.13(1.05,1.21)$ & $0.91(0.83,1.00)$ \\
\hline $38.0-38.4$ & $1,339 / 5,846(22.9)$ & $1.36(1.25,1.47)$ & $0.93(0.84,1.02)$ \\
\hline $38.5-38.9$ & $698 / 2,477(28.2)$ & $1.79(1.62,1.98)$ & $1.10(0.97,1.25)$ \\
\hline $39.0-39.4$ & $339 / 806(42.1)$ & $3.31(2.85,3.84)$ & $1.62(1.34,1.96)$ \\
\hline $39.5-39.9$ & $142 / 262(54.2)$ & $5.40(4.21,6.92)$ & $1.94(1.40,2.67)$ \\
\hline $40.0+$ & $131 / 180(72.0)$ & $12.20(8.75,17.00)$ & $2.97(1.95,4.52)$ \\
\hline \multicolumn{4}{|c|}{ CNS infection $(n=2,463)$} \\
\hline$<36.0$ & 7/42 (16.7) & $1.86(0.78,4.43)$ & $2.15(0.82,5.62)$ \\
\hline $36.0-36.4$ & $14 / 100(14.0)$ & $1.51(0.79,2.88)$ & $1.89(0.88,4.04)$ \\
\hline $36.5-36.9$ & $31 / 253(12.3)$ & $1.30(0.79,2.12)$ & $1.78(1.03,3.08)$ \\
\hline $37.0-37.4$ & $43 / 442(9.7)$ & 1.00 & 1.00 \\
\hline $37.5-37.9$ & $41 / 438(9.4)$ & $0.96(0.61,1.50)$ & $1.15(0.70,1.91)$ \\
\hline $38.0-38.4$ & $52 / 444(11.7)$ & $1.23(0.80,1.89)$ & $1.25(0.78,2.02)$ \\
\hline $38.5-38.9$ & $50 / 321(15.6)$ & $1.71(1.11,2.65)$ & $1.36(0.83,2.22)$ \\
\hline $39.0-39.4$ & $32 / 247(13.0)$ & $1.38(0.85,2.25)$ & $1.20(0.70,2.07)$ \\
\hline $39.5-39.9$ & $17 / 115(14.8)$ & $1.61(0.88,2.94)$ & $1.30(0.67,2.55)$ \\
\hline $40.0+$ & 8/61 (13.1) & $1.40(0.62,3.14)$ & $1.08(0.43,2.72)$ \\
\hline
\end{tabular}

Tests for interaction between TBI/stroke and CNS infection:

${ }^{\text {a }} P<0.0001$

b $P=0.02$

Table 3 In-hospital mortality and odds ratio (unadjusted and adjusted) for hospital mortality, relative to normothermia (37-37.4 $\left.{ }^{\circ} \mathrm{C}\right)$, for UK patients

\begin{tabular}{|c|c|c|c|}
\hline Peak temp $\left({ }^{\circ} \mathrm{C}\right)$ & $\begin{array}{l}\text { In-hospital mortality } \\
\text { deaths, } N(\%)\end{array}$ & $\begin{array}{l}\text { Unadjusted odds ratio for } \\
\text { in-hospital mortality } \\
(95 \% \mathrm{CI})^{\mathrm{a}}\end{array}$ & $\begin{array}{l}\text { Adjusted odds ratio } \\
\text { for in-hospital mortality } \\
(95 \% \mathrm{CI})^{\mathrm{b}}\end{array}$ \\
\hline \multicolumn{4}{|c|}{ TBI/stroke $(n=45,038)$} \\
\hline$<36.0$ & $931 / 1,266(73.5)$ & $7.07(5.61,8.91)$ & $4.35(3.51,5.40)$ \\
\hline $36.0-36.4$ & $1,312 / 2,741(47.9)$ & $2.34(1.97,2.77)$ & $2.15(1.88,2.46)$ \\
\hline $36.5-36.9$ & $2,414 / 7,244(33.3)$ & $1.27(1.14,1.42)$ & $1.45(1.31,1.61)$ \\
\hline $37.0-37.4$ & $3,244 / 11,497(28.2)$ & 1.00 & 1.00 \\
\hline $37.5-37.9$ & $3,084 / 10,249(30.1)$ & $1.10(0.98,1.22)$ & $0.98(0.90,1.07)$ \\
\hline $38.0-38.4$ & $2,263 / 6,820(33.2)$ & $1.26(1.08,1.47)$ & $0.97(0.88,1.08)$ \\
\hline $38.5-38.9$ & $1,225 / 3,162(38.7)$ & $1.61(1.33,1.95)$ & $1.11(0.95,1.30)$ \\
\hline $39.0-39.4$ & $669 / 1,287(52.0)$ & $2.75(2.21,3.43)$ & $1.59(1.35,1.88)$ \\
\hline $39.5-39.9$ & $304 / 474(64.1)$ & $4.55(3.34,6.21)$ & $2.46(1.90,3.19)$ \\
\hline \multirow{2}{*}{\multicolumn{4}{|c|}{ CNS infection $(n=6,396)$}} \\
\hline & & & \\
\hline$<36.0$ & $30 / 75(40.0)$ & $2.79(1.70,4.57)$ & $2.81(1.48,5.33)$ \\
\hline $36.0-36.4$ & $83 / 321(25.9)$ & $1.46(1.08,1.98)$ & $1.36(0.94,1.97)$ \\
\hline $36.5-36.9$ & $189 / 871(21.7)$ & $1.16(0.95,1.42)$ & $1.22(0.94,1.58)$ \\
\hline $37.0-37.4$ & 246/1,277 (19.3) & 1.00 & 1.00 \\
\hline $37.5-37.9$ & $202 / 1,223(16.5)$ & $0.83(0.68,1.02)$ & $0.74(0.59,0.94)$ \\
\hline $38.0-38.4$ & $148 / 1,016(14.6)$ & $0.71(0.57,0.89)$ & $0.62(0.48,0.81)$ \\
\hline $38.5-38.9$ & $116 / 735(15.8)$ & $0.79(0.61,1.01)$ & $0.63(0.46,0.87)$ \\
\hline $39.0-39.4$ & 88/501 (17.6) & $0.89(0.69,1.16)$ & $0.71(0.52,0.97)$ \\
\hline $39.5-39.9$ & $49 / 225(21.8)$ & $1.17(0.84,1.62)$ & $0.95(0.64,1.39)$ \\
\hline $40.0+$ & 43/152 (28.3) & $1.65(1.12,2.45)$ & $1.00(0.65,1.56)$ \\
\hline
\end{tabular}

Tests for interaction between TBI/stroke and CNS infection:

a $P<0.0001$

b $P<0.0001$ 

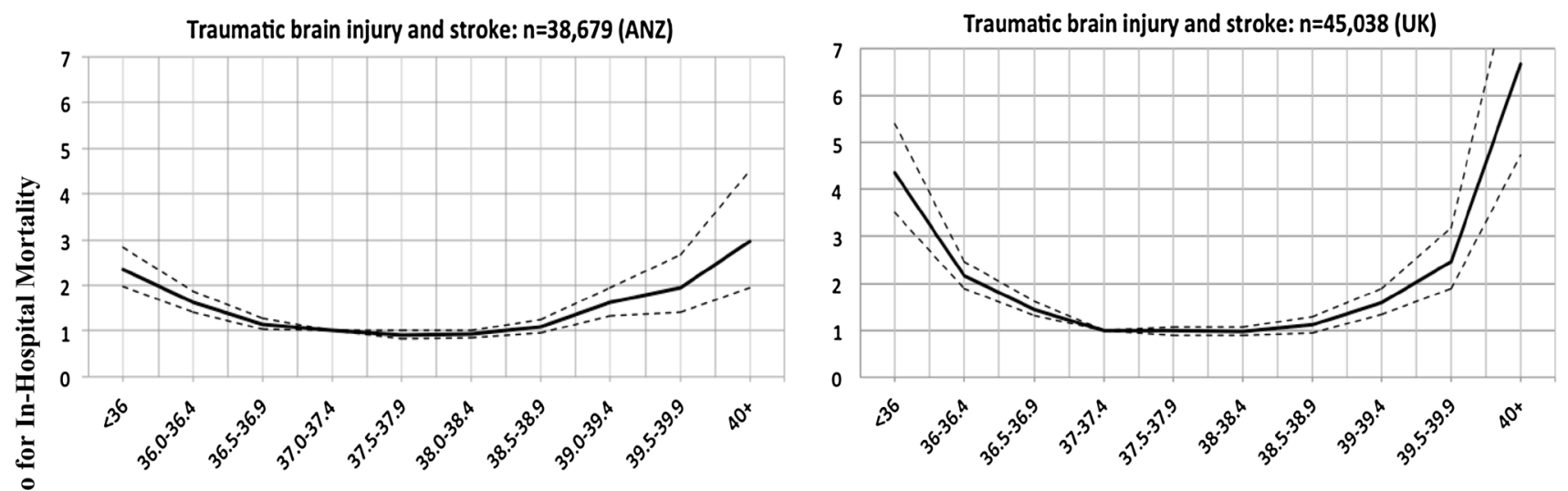

Central nervous system infection; $\mathrm{n}=2463$ (ANZ)
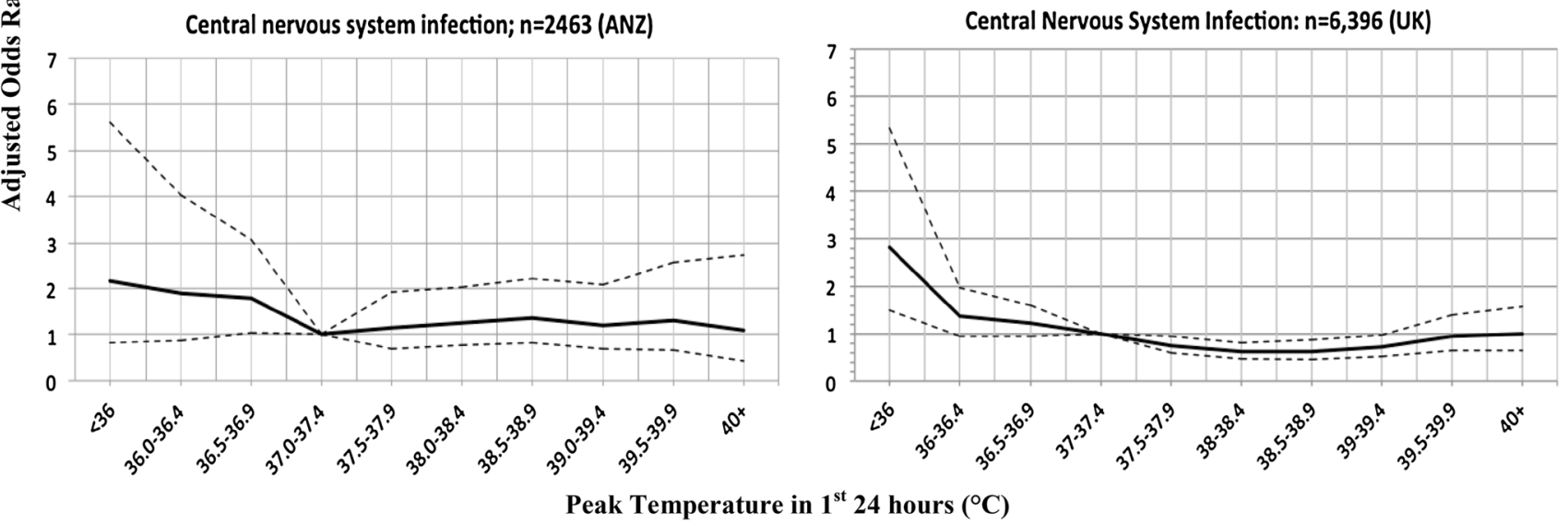

Fig. $1 \mathrm{ANZ}$ and UK data showing adjusted odds ratios for inhospital mortality versus peak temperature in the first $24 \mathrm{~h}$ after ICU admission: traumatic brain jury and stroke versus central

Table 1 demonstrates the baseline characteristics, physiology and outcomes for patients with acute neurological diseases in the ANZ and UK cohorts. The UK cohort had a higher hospital mortality than the ANZ cohort (TBI/stroke 35 vs. $22 \%$ and CNS infection 19 vs. $12 \%$ respectively; $P<0.0001)$.

Associations between peak temperature recorded in the first $24 \mathrm{~h}$ of ICU admission and hospital mortality, relative to the risk at a normal temperature between 37 and $37.4{ }^{\circ} \mathrm{C}$, are shown in Tables 2 and 3 and Figs. 1 and 2. The pattern of risk of death was similar for TBI, ischaemic stroke and haemorrhagic stroke. For both the ANZ $(P=0.02)$ and UK $(P<0.0001)$ cohorts there was a significant interaction between early peak temperature and CNS infection, indicating that the nature of the relationship between in-hospital mortality and peak temperature differed between TBI/stroke and CNS infection.

For the CNS infection group, in the ANZ cohort $(n=2,463)$, there was no significant increase in the adjusted risk of death across the range of peak temperatures, compared to normothermia. However, in the UK cohort $(n=6,396)$, there was a reduction in the risk of death between 37.5 and $39.4{ }^{\circ} \mathrm{C}$ [adjusted OR between

nervous system infection (test for interaction between TBI/stroke and CNS infection for ANZ and UK cohorts was $P=0.02$ and $P<0.0001$ respectively)

$0.62(0.48,0.81)$ and $0.74(0.59,0.94)$ within this range of temperature], compared to normothermia. Additionally, there was no increase in the risk of death for temperature above $39.5{ }^{\circ} \mathrm{C}$, compared to normothermia.

For the TBI/stroke group, in both the ANZ $(n=38,679)$ and UK cohorts $(n=45,038)$, there was no increase in the adjusted risk of death between 37 and $39^{\circ} \mathrm{C}$, in comparison to normothermia, but the risk of death increased below $37^{\circ} \mathrm{C}$ and above $39^{\circ} \mathrm{C}$.

\section{Discussion}

Statement of principal findings

Using two large, independent, multi-centric, geographically distinct and representative databases, employing different risk prediction models to adjust for illness severity and different methods to classify patients into TBI/stroke and CNS infection, we report three key findings. Firstly, the relationship between peak temperature in the first $24 \mathrm{~h}$ after ICU admission and inhospital mortality differs for patients with TBI/stroke 

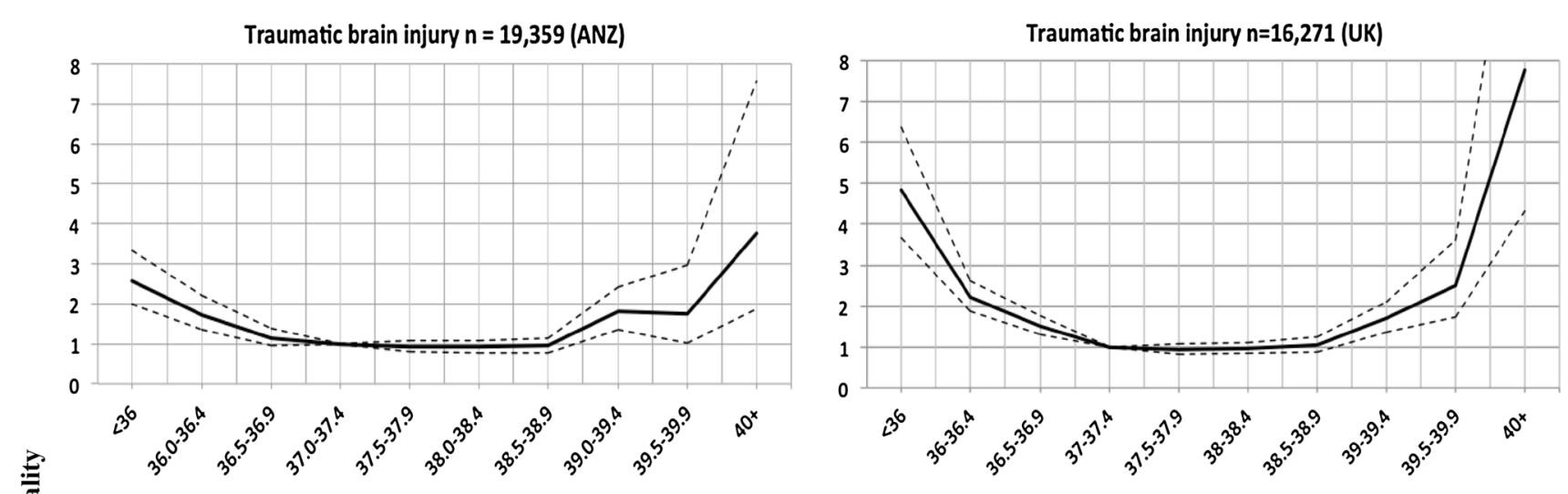

\section{Haemorrhagic stroke $n=14,144$ (ANZ)}
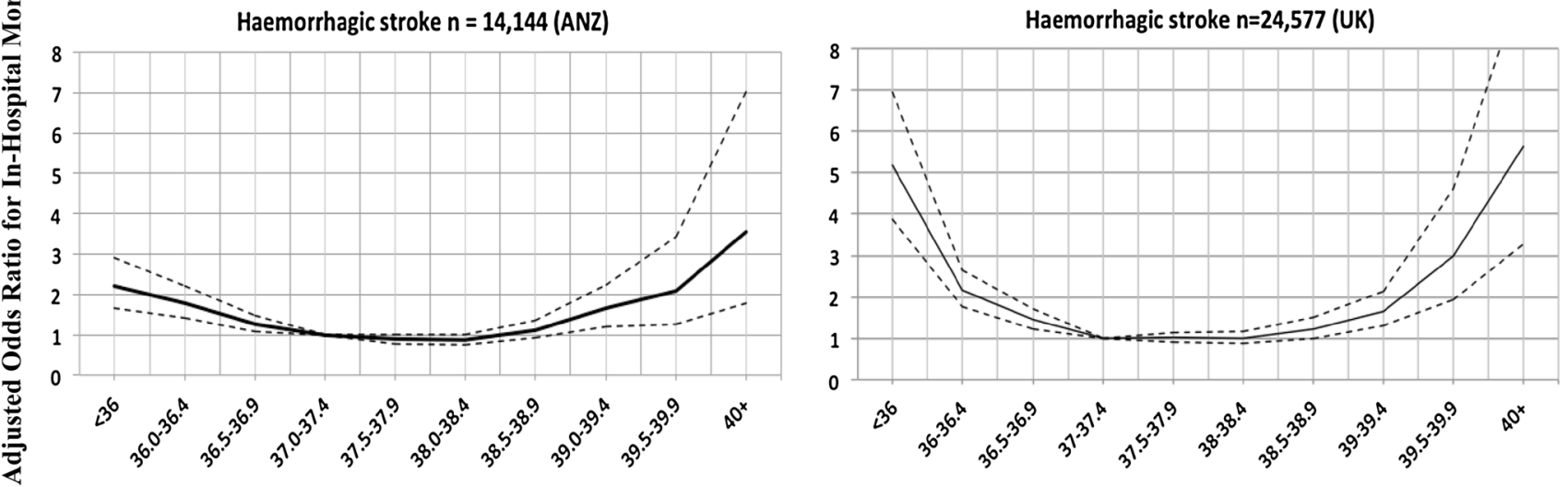

Ischaemic stroke $n=5,176$ (ANZ)
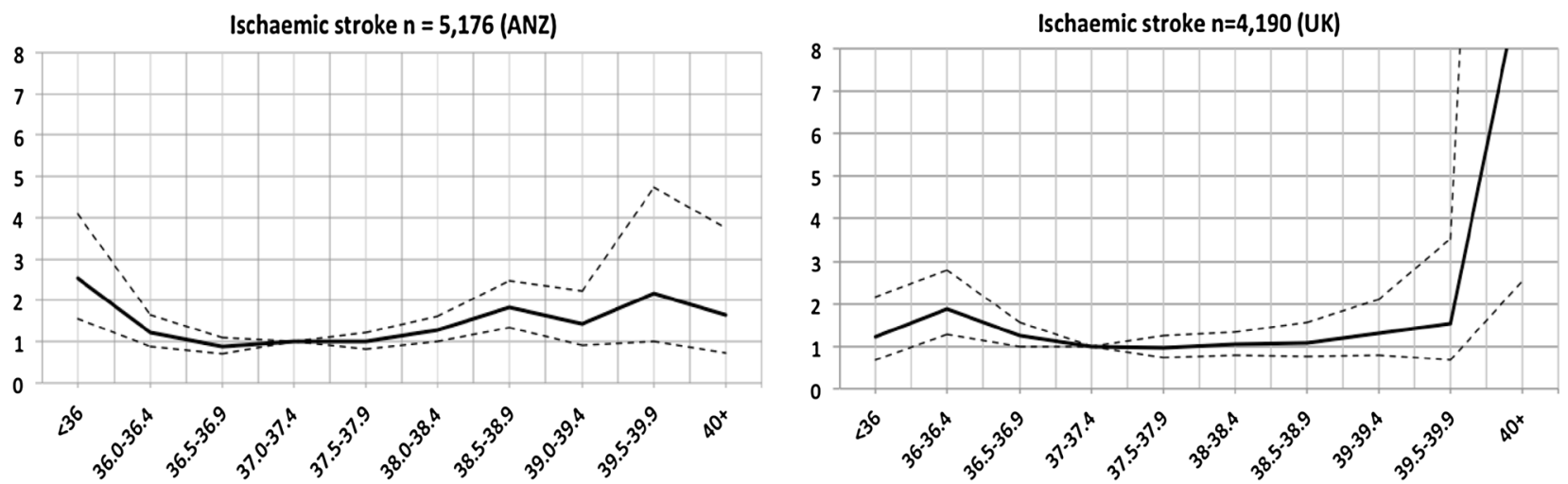

Peak Temperature in $1^{\text {st }} 24$ hours $\left({ }^{\circ} \mathrm{C}\right)$

Fig. 2 ANZ and UK data showing adjusted odds ratios for in-hospital mortality versus peak temperature in the first $24 \mathrm{~h}$ after ICU admission: traumatic brain injury, acute ischaemic stroke and subarachnoid haemorrhage/intracerebral haemorrhage

compared to those with a CNS infection. Secondly, in comparison to patients with CNS infection that are normothermic, the presence of an elevated temperature is not associated with an increased risk of death. Thirdly, in comparison to patients with $\mathrm{TBI} / \mathrm{stroke}$ that are normothermic, there was no change in the risk of death for patients with an early peak temperature of between 37 and $39^{\circ} \mathrm{C}$, but there was an increase in the risk of death above $39{ }^{\circ} \mathrm{C}$ and below $37{ }^{\circ} \mathrm{C}$.
Relationship to previous work and study significance

The finding that the pattern of risk is different for TBI/ stroke compared to CNS infection challenges the traditional assumption that avoiding hyperthermia is desirable for all neurological diseases. This finding is consistent with animal data that fever in the context of infection may be a component of an adaptive, beneficial response [10, $11,35,36]$; this finding is also compatible with previous 
cohort studies [24-26] of critically ill patients with systemic infection. Our study contradicts the findings of a smaller, previously published observational study of meningitis [37]. That elevated peak temperature is not associated with an increased risk of death in patients with CNS infection is biologically plausible, given the sensitivity of certain microbial species ( $N$. meningitides [27] and $S$. pneumonia [28]) to the higher peak temperatures we observed.

The finding for patients with TBI/stroke, that the risk of death does not increase until temperature exceeds $39^{\circ} \mathrm{C}$, is consistent with animal models of TBI/stroke that compare induced hyperthermia $\left(\geq 39{ }^{\circ} \mathrm{C}\right)$ to induced normothermia $\left(37^{\circ} \mathrm{C}[38-40]\right.$ or $\left.38^{\circ} \mathrm{C}[16]\right)$, but contrasts with smaller clinical cohort studies that report an association between temperature below $39^{\circ} \mathrm{C}[19,22]$ and adverse outcomes $\left(37.5^{\circ} \mathrm{C}[2,41], 37.9^{\circ} \mathrm{C}\right.$ [20], $38^{\circ} \mathrm{C}$ [42] and $38.5^{\circ} \mathrm{C}$ [43]). At present there are no agreed definitions of normothermia and no randomised clinical studies [13, 44, 45] confirming that the maintenance of normothermia improves patient-centred outcomes. Our study may help generate hypotheses by assisting with the formulation of a definition of normothermia for patients with TBI/stroke that could be tested in clinical trials.

The finding that hypothermia is associated with an increased risk of death for the stroke and TBI group is complex to interpret. It may be compatible with the uncertain signal from the many clinical trials evaluating induced hypothermia [46] for TBI and clinical trials of other patient groups that suggest benefit with avoiding iatrogenic hypothermia [47-49]; alternatively, it is also possible that spontaneous hypothermia may be a marker of more severe injury or that rewarming a patient that presents with spontaneous hypothermia is associated with increased mortality [50].

The difference in hospital mortality between the ANZ and UK cohorts may be explained by the increased illness severity (lower GCS and higher mechanical ventilation rate during the first $24 \mathrm{~h}$ of ICU admission) of the UK cohort. The difference in illness severity and the smaller number of patients with CNS infection in the ANZ cohort compared to the UK cohort may also partially explain the difference in the risk of death between 37.5 and $39.4{ }^{\circ} \mathrm{C}$; differences in unmeasured confounders (such as genetic patient differences or microbial resistance patterns) may offer alternative explanations.

\section{Strengths and limitations of the study}

Our study has several strengths. It used two large, independent, multinational databases that included 92,576 patients with an admission diagnosis attributable to an acute neurological disease. It used one database to test the hypothesis and the second database to validate the results, increasing the external validity of the findings. The data were independently collected by multiple trained data collectors for the purpose of audit and are unlikely to be subject to bias in relation to the recording of body temperature in the different groups of patients studied. The outcome (hospital mortality) is objective and easily verifiable, thus unlikely to be affected by ascertainment error or bias. Collection of validated markers for severity of illness allowed the adjusted odds ratio for the risk of mortality to be calculated by multivariate analysis. Finally, the differential association of fever with outcome in the two groups is statistically strong.

There are a several limitations that mainly relate to the specific information available in the two databases. Firstly, it was not possible to control for antipyretic use or physical cooling in the multivariate analysis, but these interventions are variably used in clinical practice $[4,8]$ (40-60\% of patients may be administered pharmacological agents and 21-25\% [4, 8, 51] receive physical cooling) and have not been shown to improve outcome $[13,44]$. Secondly, we were unable to control for the potential confounding role of shivering and the management of shivering between the two groups [for example, in contrast to the management of CNS infection, TBI management is often protocolised, with stepwise use of sedation and other strategies to control brain oedema that may also reduce the incidence and severity of shivering; such an approach may lead to "controlled" hypothermia with the relative absence of shivering and tachycardia in patients with TBI, and "uncontrolled" hypothermia occurring with more frequent shivering and tachycardia in patients with CNS infection. The latter may be associated with adverse events related to (for example) myocardial stress]. Thirdly, the use of a single peak temperature does not allow us to gain an understanding of the relationship between other temperature parameters (such as the proportion of time above a specified threshold or temperature variability) and outcome for the two study groups. Additionally, we studied the first $24 \mathrm{~h}$ after intensive care admission and cannot comment on the relationship between temperature and outcome during other time periods. It is plausible that fever control could have different effects in the early and later stages of infective illnesses (for example by effects on host response and cerebral swelling respectively). Future studies could address these issues. Fourthly, age-related or illness severity-related differences in the inflammatory/infective response may confound the interpretation of the difference between CNS infection and the trauma/stroke group. However we adjusted for age and illness severity in the multivariate model. Fifthly, adjustments for illness severity were based on data collected concurrently with the peak temperature data (it would be preferable to have determined the illness severity prior to the collection of the temperature data). Sixthly, the accepted endpoint for stroke and TBI clinical trials is a composite measure of death and disability measured at 6 months and not 
hospital outcome. Lastly, some patients were excluded because of missing data; however, these data may be missing at random.

\section{Conclusion}

The association between early fever and hospital mortality for critically ill patients with acute neurological diseases is different for patients with CNS infection compared to patients with TBI and stroke. For the group with CNS infection, fever was not associated with an increased risk of death, compared to normothermia, but for patients with stroke and TBI, temperature below $37{ }^{\circ} \mathrm{C}$ and above $39{ }^{\circ} \mathrm{C}$ was associated with an increased risk of death. These data may be useful for hypothesis generation for clinical trials evaluating the efficacy of normothermia for acute neurological diseases.

Acknowledgments We would like to thank all the data collectors at each of the hospitals in the UK and Australia and New Zealand. In addition we thank Prof. Rustam Salman Al-Shahi and Dr. Frédérique Schortgen for offering their feedback and suggestions on this manuscript.

Conflicts of interest The authors report no conflicts of interests in relation to this manuscript.

Open Access This article is distributed under the terms of the Creative Commons Attribution Noncommercial License which permits any noncommercial use, distribution, and reproduction in any medium, provided the original author(s) and the source are credited.

\section{References}

1. WHO (2006) Neurological disorders: public health challenges (World Health Organisation). http://www.who.int/ mental_health/neurology/chapter_2 neuro_disorders_public_h_challenges. pdf. Accessed 30 Jan $201 \overline{5}$

2. Castillo J, Dávalos A, Marrugat J, Noya M (1998) Timing for fever-related brain damage in acute ischemic stroke. Stroke 29:2455-2460

3. Reith J, Jorgensen HS, Pedersen PM et al (1996) Body temperature in acute stroke: relation to stroke severity, infarct size, mortality, and outcome. Lancet 347:422-425

4. Stocchetti N, Rossi S, Zanier ER, Colombo A, Beretta L, Citerio G (2002) Pyrexia in head-injured patients admitted to intensive care. Intensive Care Med 28:1555-1562

5. Oliveira-Filho J, Ezzeddine MA, Segal AZ et al (2001) Fever in subarachnoid hemorrhage: relationship to vasospasm and outcome. Neurology 56:1299-1304

6. Kilpatrick MM, Lowry DW, Firlik AD, Yonas H, Marion DW (2000) Hyperthermia in the neurosurgical intensive care unit. Neurosurgery 47:850-855 (discussion 5-6)

7. Chaudhuri A, Martin P, Kennedy P et al (2008) EFNS guideline on the management of community-acquired bacterial meningitis: report of an EFNS Task Force on acute bacterial meningitis in older children and adults. Eur J Neurol 15:649-659

8. Saxena MK, Taylor CB, Hammond NE et al (2013) Temperature management in patients with acute neurological lesions: an Australian and New Zealand point prevalence study. Crit Care Resusc15:110-118
9. Seguin P, Roquilly A, Mimoz $\mathrm{O}$ et al (2012) Risk factors and outcomes for prolonged versus brief fever: a prospective cohort study. Crit Care 16:R150

10. Mackiowak P (1998) Concepts of fever. Arch Intern Med 158:1870-1881

11. Kluger MJ (1979) Fever in ectotherms: evolutionary implications. Am Zool 19:295-304

12. Saxena M, Andrews PJ, Cheng A, Deol $\mathrm{K}$, Hammond N (2014) Modest cooling therapies $\left(35^{\circ} \mathrm{C}\right.$ to $\left.37.5^{\circ} \mathrm{C}\right)$ for traumatic brain injury. Cochrane Database Syst Rev CD006811

13. Den Hertog HM, van der Worp HB, Tseng M-C, Dippel D (2009) Cooling therapy for acute stroke. Cochrane Database Syst Rev CD001247

14. Tunkel AR, Hartman BJ, Kaplan SL et al (2004) Practice guidelines for the management of bacterial meningitis. Clin Infect Dis 39:1267-1284

15. Busto R, Dietrich WD, Globus MY, Ginsberg MD (1989) The importance of brain temperature in cerebral ischemic injury. Stroke 20:1113-1114

16. Baena RC, Busto R, Dietrich WD, Globus MY, Ginsberg MD (1997) Hyperthermia delayed by 24 hours aggravates neuronal damage in rat hippocampus following global ischemia. Neurology 48:768-773

17. Dietrich WD, Busto R, Valdes I, Loor Y (1990) Effects of normothermic versus mild hyperthermic forebrain ischemia in rats. Stroke 21:1318-1325
18. Dietrich WD, Alonso O, Halley M, Busto R (1996) Delayed posttraumatic brain hyperthermia worsens outcome after fluid percussion brain injury: a light and electron microscopic study in rats. Neurosurgery 38:533-541 (discussion 41)

19. Hajat C, Hajat S, Sharma P (2000) Effects of poststroke pyrexia on stroke outcome: a meta-analysis of studies in patients. Stroke 31:410-414

20. Azzimondi G, Bassein L, Nonino F et al (1995) Fever in acute stroke worsens prognosis. A prospective study. Stroke 26:2040-2043

21. Jorgensen HS, Reith J, Nakayama H et al (2001) Potentially reversible factors during the very acute phase of stroke and their impact on the prognosis: is there a large therapeutic potential to be explored? Cerebrovasc Dis 11:207-211

22. Greer DM, Funk SE, Reaven NL, Ouzounelli M, Uman GC (2008) Impact of fever on outcome in patients with stroke and neurologic injury: a comprehensive meta-analysis. Stroke 39:3029-3035

23. Young P, Saxena M, Beasley R (2011) Fever and antipyresis in infection. Med J Aust 195:458-459

24. Kushimoto S, Gando S, Saitoh D et al (2013) The impact of body temperature abnormalities on the disease severity and outcome in patients with severe sepsis: an analysis from a multicenter, prospective survey of severe sepsis. Crit Care 17:R271 
25. Lee BH, Inui D, Suh GY et al (2012) Association of body temperature and antipyretic treatments with mortality of critically ill patients with and without sepsis: multi-centered prospective observational study. Crit Care 16:R33

26. Young P, Saxena MK, Beasley CRW et al (2011) Early peak temperature and mortality in critically ill patients with or without infection. Intensive Care Med 38:437-444

27. Moench M (1926) A study of the heat sensitivity of the meningococcus in vitro within the range of therapeutic temperatures. J Lab Clin Med 57:665-676

28. Hensch PS, Slocumb CH, Popp WC (1935) Results for gonorrhea arthritis, chronic infectious (atrophic) arthritis and other forms of "rheumatism". JAMA 104:1779-1790

29. Paul E, Bailey M, Pilcher D (2013) Risk prediction of hospital mortality for adult patients admitted to Australian and New Zealand intensive care units: development and validation of the Australian and New Zealand Risk of Death model. J Crit Care 28:935-941

30. Harrison DA, Parry GJ, Carpenter JR, Short A, Rowan K (2007) A new risk prediction model for critical care: the Intensive Care National Audit \& Research Centre (ICNARC) model. Crit Care Med 35:1091-1098

31. Kaukonen K-M, Bailey M, Suzuki S, Pilcher D, Bellomo R (2014) Mortality related to severe sepsis and septic shock among critically ill patients in Australia and New Zealand, 2000-2012. JAMA 311:1308-1316

32. Stow PJ, Hart GK, Higlett T et al (2006) Development and implementation of a high-quality clinical database: the Australian and New Zealand Intensive Care Society Adult Patient Database. J Crit Care 21:133-141

33. Harrison DA, Brady AR, Rowan K (2004) Case mix, outcome and length of stay for admissions to adult, general critical care units in England, Wales and Northern Ireland: the Intensive Care National Audit \& Research Centre Case Mix Programme Database. Crit Care 9:S1
34. Knaus WA, Draper EA, Wagner DP, Zimmerman JE (1985) APACHE II: a severity of disease classification system. Crit Care Med 13:818-829

35. Starks PT, Blackie CA, Seeley TD (2000) Fever in honeybee colonies. Naturwissenschaften 87:229-231

36. Blanford S, Thomas MB, Langewald J (1998) Behavioural fever in the Senegalese grasshopper, Oedaleus senegalensis, and its implications for biological control using pathogens. Ecol Entomol 23:9-14

37. de Jonge RC, van Furth AM, Wassenaar M, Gemke RJ, Terwee CB (2010) Predicting sequelae and death after bacterial meningitis in childhood: a systematic review of prognostic studies. BMC Infect Dis 10:232

38. Sacho RH, Childs C (2008) The significance of altered temperature after traumatic brain injury: an analysis of investigations in experimental and human studies: part 2. Br J Neurosurg 22:497-507

39. Aiyagari V, Diringer MN (2007) Fever control and its impact on outcomes: what is the evidence? J Neurol Sci 261:39-46

40. Marion DW (2004) Controlled normothermia in neurologic intensive care. Crit Care Med 32:s43-s45

41. den Hertog HM, van der Worp HB, van Gemert HMA et al (2011) An early rise in body temperature is related to unfavorable outcome after stroke: data from the PAIS study. J Neurol 258:302-307

42. Li J, Jiang J-Y (2012) Chinese Head Trauma Data Bank: effect of hyperthermia on the outcome of acute head trauma patients. J Neurotrauma 29:96-100

43. Diringer MN, Reaven NL, Funk SE, Uman GC (2004) Elevated body temperature independently contributes to increased length of stay in neurologic intensive care unit patients [Erratum appears in Crit Care Med. 2004 Oct;32(10):2170]. Crit Care Med 2004(32):1489-1495
44. Saxena M, Andrews PJD, Cheng A (2008) Modest cooling therapies (35 degrees $\mathrm{C}$ to 37.5 degrees $\mathrm{C}$ ) for traumatic brain injury. Cochrane Database Syst Rev CD006811

45. Den Hertog HM, van der Worp HB, van Gemert HMA et al (2009) The paracetamol (acetaminophen) in stroke (PAIS) trial: a multicentre, randomised, placebo-controlled, phase III trial. Lancet Neurol 8:434-440

46. Sydenham E, Roberts I, Alderson P (2009) Hypothermia for traumatic head injury. Cochrane Database Syst Rev CD001048

47. Arons MM, Wheeler AP, Bernard GR et al (1999) Effects of ibuprofen on the physiology and survival of hypothermic sepsis. Crit Care Med 27:699-707

48. Kurz A, Sessler DI, Lenhardt R (1996) Perioperative normothermia to reduce the incidence of surgical-wound infection and shorten hospitalization. N Engl J Med 334:1209-1216

49. Frank SM, Fleisher LA, Breslow MJ et al (1997) Perioperative maintenance of normothermia reduces the incidence of morbid cardiac events. JAMA 277:1127-1134

50. Clifton GL, Miller ER, Choi SC et al (2002) Hypothermia on admission in patients with severe brain injury. J Neurotrauma 19:293-301

51. Frank B, Fulton R, Weimar C, Lees K, Sanders R (2013) Use of paracetamol in ischaemic stroke patients: evidence from VISTA. Acta Neurol Scand 128:172-177 